\title{
Two-dimensional THM modelling of the large scale natural hydrothermal circulation at Soultz-sous-Forêts
}

\author{
Vincent Magnenet ${ }^{1 *}$, Christophe Fond ${ }^{1}$, Albert Genter ${ }^{2}$ and Jean Schmittbuhl ${ }^{3}$
}

\author{
${ }^{*}$ Correspondence: \\ vmagnenet@unistra.fr \\ 1 ICube Laboratory, UMR CNRS \\ 7357, 72, Route du Rhin, CS 315 \\ F-67411, Illkirch CEDEX, France \\ Full list of author information is \\ available at the end of the article
}

\begin{abstract}
Background: A two-dimensional numerical model is developed for the Soultz-sous-Forêts reservoir from an idealized cross-section containing six homogeneous horizontal layers. The considered constitutive equations are those of homogenized saturated porous media involving Thermo-Hydro-Mechanical (THM) couplings, and most of materials properties (for brine and rocks) are taken dependent on temperature and pressure.
\end{abstract}

Methods: The constitutive equations are solved in transient regime with the finite element software Code_Aster to reach a stationary state of the reservoir.

Results: We show that a large scale natural convection is compatible with present boundary conditions if the permeability of the reservoir is of the order of $1.0 \times 10^{-14} \mathrm{~m}^{2}$. Convection cells are of the order of $1.3 \mathrm{~km}$ in width and we analyze several vertical profiles and maps of physical properties.

Conclusions: A stationary convective solution at large scale is highlighted.

Keywords: Geothermal reservoir; Finite element method; Thermo-hydro-mechanical model; Natural convection

\section{Background}

The interest of obtaining a numerical and coupled model of a given geothermal reservoir is fourfold. First, it allows the physical integration of laboratory measurements (rock physics), such as well logging, well head parameters, geological description, and geophysics field measurements. It shows how data are precious input parameters of the model and gives them an utility of great importance. Furthermore, numerical simulations can not only help to interpret and understand physical processes measured with laboratory and field experiments but also address and quantify the relevant processes occurring in a reservoir. Secondly, it provides a direct model based on geophysical inversion of field measurements: fluid flow, fluid pressure, temperature profile, seismicity monitoring, deformation of the ground surface (INSAR/GPS) related to reservoir modification, and gravity or electromagnetic geophysical measurements. Another advantage of simulating the reservoir behaviour is the possibility to analyse the sensitivities of parameters involved in the hydrothermal circulation (or in other physical processes). This analysis can lead to the identification of relevant processes occurring in the reservoir and material properties

() 2014 Magnenet et al.; licensee Springer. This is an Open Access article distributed under the terms of the Creative Commons Attribution License (http://creativecommons.org/licenses/by/4.0), which permits unrestricted use, distribution, and reproduction in any medium, provided the original work is properly credited. 
having the greatest influence on the model outputs, thus providing useful informations for the planification of new experimental investigations. Finally, the model can also be used as a decision tool for drilling and implacement planning, stimulation and exploitation.

Several models have been developed in literature to reproduce field measurements or to predict the value of physical properties in reservoirs. The most simplified approaches are unidimensional. They couple hydraulic with thermics as in (Pasquale et al. 2011b), but more complex geometries have been considered in two dimensions as in (Guillou-Frottier et al. 2013; Kohl et al. 2000; Cerminara and Fasano 2012; Magri et al. 2010) or in three dimensions (Bächler et al. 2003; Kohl and Mégel 2007). Most of these models aim at reproducing or predicting the temperature profile measured in wells and/or hydraulic data obtained during injection and production phases (water flow, water pressure and temperature vs. time). Some numerical models have also been developed to account for mechanical, thermal and hydraulic couplings at the same time, with a simplified geometry of the fault network, see, e.g. Kohl et al. (1995) or Gelet et al. (2012). In addition, other thermodynamical aspects have been addressed like chemical couplings in Bächler and Kohl (2005).

The present work is in line with these previous approaches and can be viewed as another thermo-hydro-mechanical (THM) model of the Soultz-sous-Forêts geothermal reservoir. Our geomechanical model aims at solving constitutive equations using poroelastic medium theory, completed by reasonable boundary conditions. The goal is first to show the existence of a convective and stationary solution at large scale, considering only the regional stratigraphy and known rheophysic properties of the rock matrix and the saturating brine. This solution, different from the Elder problem (Elder 1967), is the starting point to proceed to a stability analysis of the reservoir when it is submitted to some mechanical, thermal or hydraulic perturbation specific of stimulation or production phases. As it will be shown below, the constitutive equations governing the evolution of the reservoir are strongly nonlinear. Consequently, one expects that the time evolution of the reservoir may be highly sensitive to initial conditions and that it can reach several metastable equilibrium states during the simulation. Given the complexity of the stability analysis, we focus in this paper on the existence of a stationary state of the Soultz-sous-Forêts reservoir. We consider it at large scale (about $10 \mathrm{~km}$ in width and $5 \mathrm{~km}$ in height). Our specificity is to assume that media are homogenized, i.e. at a scale above the representative elementary volume (REV) of the well-known contribution of Coussy (2004), as porous materials saturated with a single-phase fluid but including all major THM couplings. Our work is limited to a two-dimensional modelling, as in the recent contribution from Guillou-Frottier et al. (2013). The main geological structures retained here are as follows: (i) the main sedimentary beddings of the Rhine Graben and (ii) major petrographic transitions in the granite, which are supposed to be horizontal. No fault is included in the model at this stage. Despite these strong geometrical assumptions, we aim at accounting for the rich rheologies of rocks and brine, which constitute the main contribution of the present work compared to the above mentioned studies. At last, let us notice that a transient simulation has been chosen to 'slowly' evolve towards a stationary state starting from an initial (given) state of the reservoir. Indeed, integrating the constitutive equations governing THM processes is strongly constrained by stability issues due to the non-linearity of these equations. 
The outline of the paper is the following: first, we present the constitutive equations considered in the model. We then develop numerical aspects and finally discuss the main results of our simulations.

\section{Methods}

\section{Governing equations}

The constitutive equations used in this work are those of fluid saturated porous media with THM couplings, as described in the reference book of Coussy (2004). Three forms of energy are considered: mechanical, thermal and hydraulic energies, each of them being characterized by a generalized displacement, strain (i.e. gradient of the latter) and stress (i.e. thermodynamic dual of the generalized strain, see Table 1). The local thermodynamic equilibrium and small perturbation assumptions are made. In doing so, no confusion between Eulerian and Lagrangian operators is then possible. The balance equations driving the evolution of extensive quantities associated with all forms of energies write the following:

$$
\begin{aligned}
& \nabla \cdot \boldsymbol{\sigma}+r \boldsymbol{F}^{m}=0 \quad \text { (momentum balance) } \\
& \frac{\partial m_{w}}{\partial t}+\nabla \cdot \boldsymbol{M}_{w}=0 \quad \text { (mass balance) } \\
& \boldsymbol{M}_{w} \cdot \boldsymbol{F}^{m}+\Theta=h_{w}^{m} \frac{\partial m_{w}}{\partial t}+\dot{Q}+ \\
& \nabla \cdot\left(h_{w}^{m} \boldsymbol{M}_{w}\right)+\nabla \cdot \boldsymbol{q} \text { (energy balance) },
\end{aligned}
$$

where $\sigma[\mathrm{Pa}]$ is the Cauchy stress tensor, $r\left[\mathrm{~kg} \cdot \mathrm{m}^{-3}\right]$ the total homogenized specific mass, and $\boldsymbol{F}^{m}\left[\mathrm{~N}^{\mathrm{kg}}{ }^{-1}\right]$ the massic force density (gravity in the present paper). In this work, $r$ is decomposed into two contributions, $r=r_{0}+m_{w}, r_{0}\left[\mathrm{~kg} \cdot \mathrm{m}^{-3}\right]$ being the initial total homogenized specific mass and $m_{w}\left[\mathrm{~kg} . \mathrm{m}^{-3}\right]$ the mass content of water, that is the mass of water $d m_{w}$ that entered or left an elementary volume $d V$ of the porous medium since the initial state, per unit of volume. The vector $\boldsymbol{M}_{w}\left[\mathrm{~kg} \cdot \mathrm{m}^{-2} \cdot \mathrm{s}^{-1}\right]$ appearing in Equation (2) is the massic flow of water. Concerning Equation (3), $h_{w}^{m}\left[J \cdot \mathrm{kg}^{-1}\right]$ is the specific enthalpy of water, $Q\left[\mathrm{~J} \cdot \mathrm{m}^{-3}\right]$ is the 'non-convective' heat (see below) and $\boldsymbol{q}\left[\mathrm{J} \cdot \mathrm{m}^{-2} \cdot \mathrm{s}^{-1}\right]$ the heat flow due to conduction. The radioactivity of rocks is taken into account through the heat source term $\Theta\left[\mathrm{W} \cdot \mathrm{m}^{-3}\right]$.

The balance equations must be supplemented with not only relations between generalized stresses and strains but also relations from porous medium theory. First, we use the classical decomposition of the Cauchy stress tensor into the following two contributions:

$$
\boldsymbol{\sigma}=\boldsymbol{\sigma}^{\prime}+\sigma_{p} \mathbf{1}
$$

Table 1 Set of thermodynamic variables associated with each form of energy

\begin{tabular}{lccc}
\hline Phenomenon & Generalized displacement & Generalized strain & Generalized stress \\
\hline Mechanics & $\boldsymbol{\xi}[\mathrm{m}]$ & $\boldsymbol{\epsilon}=\left(\boldsymbol{\nabla} \xi+\nabla^{\top} \xi\right) / 2$ & $\boldsymbol{\sigma}[\mathrm{Pa}]$ \\
Hydraulics & Linear strain & Cauchy stress tensor \\
& $p_{w}[\mathrm{~Pa}]$ & $\nabla p_{w}\left[\mathrm{~Pa} \cdot \mathrm{m}^{-1}\right]$ & $\boldsymbol{M}\left[\mathrm{kg} \cdot \mathrm{m}^{-2} \cdot \mathrm{s}^{-1}\right]$ \\
Thermics & & Hydraulic flow \\
& $T[\mathrm{~K}]$ & $\nabla T\left[\mathrm{~K} \cdot \mathrm{m}^{-1}\right]$ & $\boldsymbol{q}\left[\mathrm{J} \cdot \mathrm{m}^{-2} \cdot \mathrm{s}^{-1}\right]$ \\
Temperature & & Heat flow
\end{tabular}


with $\sigma^{\prime}[\mathrm{Pa}]$, the effective Cauchy stress tensor for the solid grains behaviour and $\sigma_{p}$ $[\mathrm{Pa}]$, the hydraulic stress. In this work, the behaviour of solid grains is assumed to be thermo-elastic and linear, so that we can introduce the linear total strain $\epsilon$ and the drained elasticity tensor $\mathbb{C}[\mathrm{Pa}]$ with the following incremental law:

$$
d \boldsymbol{\sigma}^{\prime}=\mathbb{C}:\left(d \boldsymbol{\epsilon}-\alpha_{0} d T \mathbf{1}\right)
$$

in which $\alpha_{0}\left[\mathrm{~K}^{-1}\right]$ stands for the linear thermal dilation of the dry material, $T[\mathrm{~K}]$ the absolute temperature and 1 the unit tensor. Below, we denote by $E[\mathrm{~Pa}]$ and $v$ the drained Young's modulus and Poisson's ratio, respectively. The porous behaviour is described by the incremental evolution of the Eulerian porosity $\phi$ and the hydraulic stress $\sigma_{p}[\mathrm{~Pa}]$ (Coussy 2004) as follows:

$$
\begin{aligned}
d \phi & =(b-\phi)\left(d \epsilon_{v}-3 \alpha_{0} d T+\frac{d p_{w}}{K_{s}}\right), \\
d \sigma_{p} & =-b d p_{w}
\end{aligned}
$$

where $b$ is the Biot coefficient, $\epsilon_{v}=\operatorname{Tr}(\boldsymbol{\epsilon})$ is the volume total strain, $p_{w}[\mathrm{~Pa}]$ is the water pressure and $K_{s}[\mathrm{~Pa}]$ is the bulk modulus of solid grains. The mass content of water can then be expressed as the variation of water mass per unit of volume between the actual state and the initial state

$$
m_{w}=\rho_{w}\left(1+\epsilon_{v}\right) \phi-\rho_{w}^{0} \phi_{0}
$$

with $\rho_{w}^{0}\left[\mathrm{~kg} \cdot \mathrm{m}^{-3}\right]$ the initial specific mass of water and $\phi_{0}$ the initial porosity.

The hydraulic and thermal phenomena are governed by the Darcy's law and Fourier's law, respectively, and most rock properties (like the specific heat at constant stress $c_{0}^{\sigma}$ or the thermal conductivity $\lambda$ ) are assumed to depend on temperature $T$ and/or porosity $\phi$ (see the next section for a detailed presentation). More precisely, if we denote by $K_{\text {int }}\left[\mathrm{m}^{2}\right]$, the intrinsic permeability, we consider the following well-known relations:

$$
\begin{aligned}
\boldsymbol{q} & =-\lambda \nabla T, \\
\boldsymbol{M}_{w} & =\frac{\rho_{w} K_{\mathrm{int}}}{\mu_{w}}\left(-\nabla p_{w}+\rho_{w} \boldsymbol{F}^{m}\right) .
\end{aligned}
$$

Since measurements of the rock permeability along the wells exhibit several orders of magnitude of variability, we decided to neglect the influence of porosity on permeability to improve the numerical stability, despite the existence of well-known models in the literature (e.g. Van-Genuchten model). In Equation (3), the non-convected heat $Q$ can be understood as the 'variation of heat per unit of volume not coming from convection nor conduction'. It comes not only from the heat produced by the volumic deformation of solid grains and water but also from the internal energy of the homogenized medium. It follows the equality

$$
\delta Q=3 \alpha_{0} K_{0} T d \epsilon_{v}-3\left[(b-\phi) \alpha_{0}+\alpha_{w} \phi\right] T d p_{w}+c_{0}^{\epsilon} d T
$$

with $K_{0}[\mathrm{~Pa}]$ the drained bulk modulus, $\alpha_{w}\left[\mathrm{~K}^{-1}\right]$ the dilation of water, and $c_{0}^{\epsilon}\left[\mathrm{J} \cdot \mathrm{kg}^{-1} \cdot \mathrm{K}^{-1}\right]$ the specific heat at constant strain. The latter is calculated from the specific heat at constant stress $c_{0}^{\sigma}$ by using the following formula (Coussy 2004):

$$
c_{0}^{\epsilon}=c_{0}^{\sigma}-9 T K_{0} \alpha_{0}^{2} .
$$




\section{Physical properties of constituents}

At this stage, the main constitutive equations have been presented, and this section is devoted to the presentation of relationships governing the evolution of physical properties with temperature, porosity, and pressure. The entire set of properties is extracted from the literature dealing with experimental investigations.

In an attempt to characterize as precisely as possible the convective movement of water and the associated heat flow, the properties of water (specific mass $\rho_{w}\left(T, p_{w}\right)$, specific enthalpy $h_{m}^{w}\left(T, p_{w}\right)$, dynamic viscosity $\mu_{w}(T)$, thermal dilation $\alpha_{w}(T)$, and specific heat $\left.c_{w}^{p}(T)\right)$ are assumed to depend on the pressure and/or temperature. In this first approach, the brine of the reservoir is treated as a pure solution of $\mathrm{NaCl}$, characterized by a mass content of about $100 \mathrm{~kg} \cdot \mathrm{m}^{-3}$ in accordance with the paper of Genter et al. (2010). If we admit a mean specific mass of brine equal to $1,000 \mathrm{~kg} \cdot \mathrm{m}^{-3}$ - corresponding to the specific mass at temperature of about $150^{\circ} \mathrm{C}$ and pressure of about $25 \mathrm{MPa}$, representative values in the reservoir - this mass content is equivalent to a molar content of 1.5 mol. $\mathrm{kg}^{-1}$. The specific mass is here governed by the following incremental relation:

$$
\frac{d \rho_{w}}{\rho_{w}}=\frac{d p_{w}}{K_{w}}-3 \alpha_{w}(T) d T,
$$

with $K_{w}[\mathrm{~Pa}]$ as the (constant) bulk modulus and $\alpha_{w}(T)$ as the thermal dilation assumed quadratic with respect to the temperature $T$

$$
\alpha_{w}(T)=a_{\alpha_{w}}+2 b_{\alpha_{w}}\left(T-T^{0}\right)+3 c_{\alpha_{w}}\left(T-T^{0}\right)^{2}
$$

where $T^{0}$ is a reference temperature equal to $293 \mathrm{~K}$. Note that Equation (13) was already used in the work of Segall and Rice (2006) but with constant thermal dilation $\alpha_{w}(T)=\alpha_{w}$ describing a linear dependence of the relative variation of density with temperature and pressure. Several other models exist in the literature, see, e.g. the review of Francke and Thorade (2010), but Equation (13) has been used because it is the law implemented in Code_Aster. Equation (13) can be rewritten in the following integral form:

$$
\rho_{w}=\rho_{w}^{0} \exp \left\{\frac{p_{w}-p_{w}^{0}}{K_{w}}-3\left[a_{\alpha_{w}}\left(T-T^{0}\right)+b_{\alpha_{w}}\left(T-T^{0}\right)^{2}+c_{\alpha_{w}}\left(T-T^{0}\right)^{3}\right]\right\}
$$

where $p_{w}^{0}=0.1 \mathrm{MPa}$ is a reference water pressure and $\rho_{w}^{0}$ is a synthetic notation for $\rho_{w}\left(T^{0}, p_{w}^{0}\right)$. The bulk modulus $K_{w}$ and the coefficients $a_{\alpha_{w}}, b_{\alpha_{w}}$ and $c_{\alpha_{w}}$ have been calibrated to make Equation (15) fit the experimental correlation proposed in Rowe and Chou (1970) evaluated for a $\mathrm{NaCl}$ mass fraction $w=0.1$ (corresponding to $100 \mathrm{~kg} \cdot \mathrm{m}^{-3}$ assuming a mean density of $1,000 \mathrm{~kg} \cdot \mathrm{m}^{-3}$ ). The result of the fit and the derived evolution of $\alpha_{w}$ with temperature are plotted in Figures 1 and 2.

Concerning the heat capacity, the quadratic correlation given in Zaytsev and Aseyev (1992) for $\mathrm{NaCl}$ solutions is used

$$
c_{w}^{p}(T)=a_{c_{w}^{p}}+b_{c_{w}^{p}}\left(T-T^{1}\right)+c_{c_{w}^{p}}\left(T-T^{1}\right)^{2}
$$

with $T^{1}=273.15 \mathrm{~K}$, see Figure 3 . The same authors propose a correlation for the thermal conductivity but only valid for a temperature varying between $0^{\circ} \mathrm{C}$ and $100^{\circ} \mathrm{C}$. We decided to extrapolate this correlation over $100^{\circ} \mathrm{C}$ with a quasi constant value by using the following exponential relation:

$$
\lambda_{w}(T)=a_{\lambda_{w}}\left(1-b_{\lambda_{w}} \exp \left[-c_{\lambda_{w}}\left(T-T^{1}\right)\right]\right)
$$




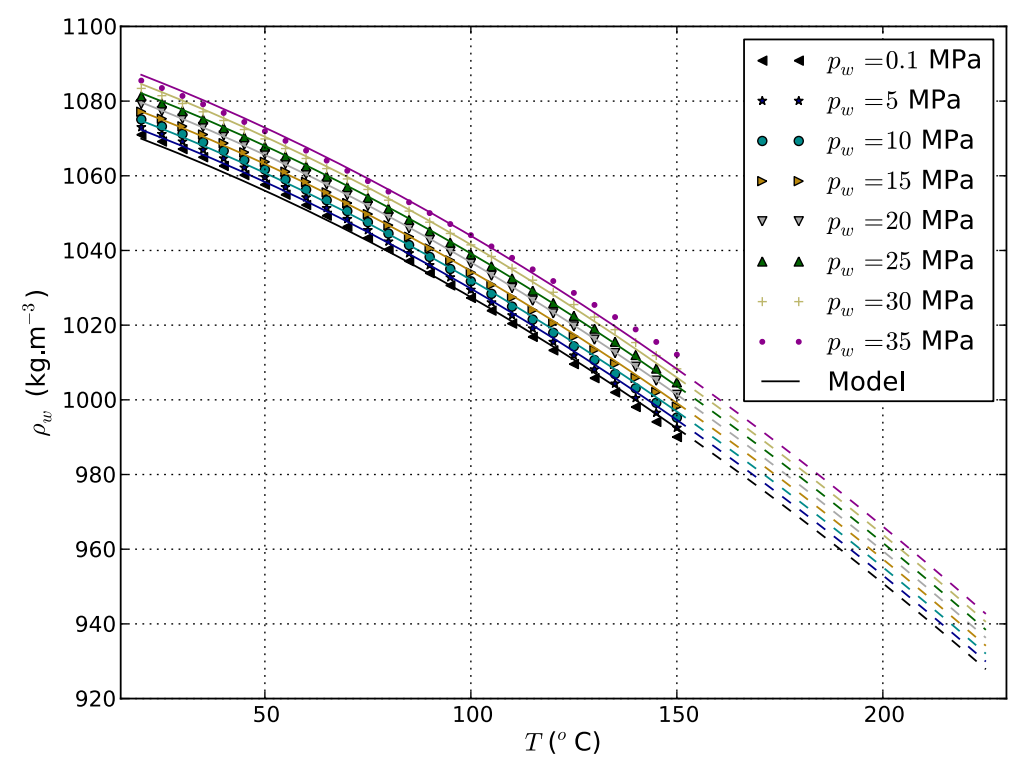

Figure 1 Experimental correlation comparison of Equation (15) with that of Rowe and Chou (1970).

Comparison of Equation (15) (plain and dotted lines) with the experimental correlation of Rowe and Chou (1970) (data points) evaluated for a $\mathrm{NaCl}$ mass fraction $w=0.1$

which is plotted in Figure 4. The viscosity of the brine is approximated by the Eyring law (Figure 5)

$$
\mu_{w}(T)=\mu_{w}^{\infty}+\Delta \mu_{w}^{\infty} \exp \left[\beta\left(T-T_{r e f}\right)\right] .
$$

fitted on the data of Rowe and Chou (1970). Finally, the specific enthalpy is governed by the following relation:

$$
d h_{w}^{m}=c_{w}^{p}(T) d T+\left[1-3 \alpha_{w}(T) T\right] \frac{d p_{w}}{\rho_{w}},
$$

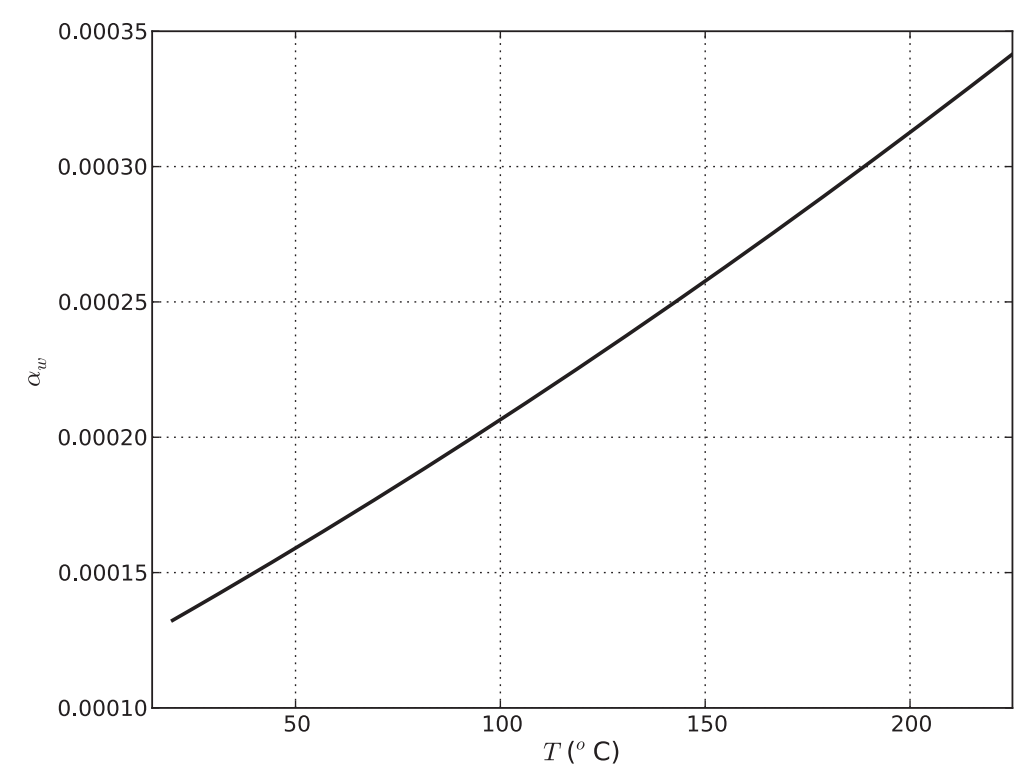

Figure 2 Evolution of the thermal dilation of brine as described by Equation (14). 


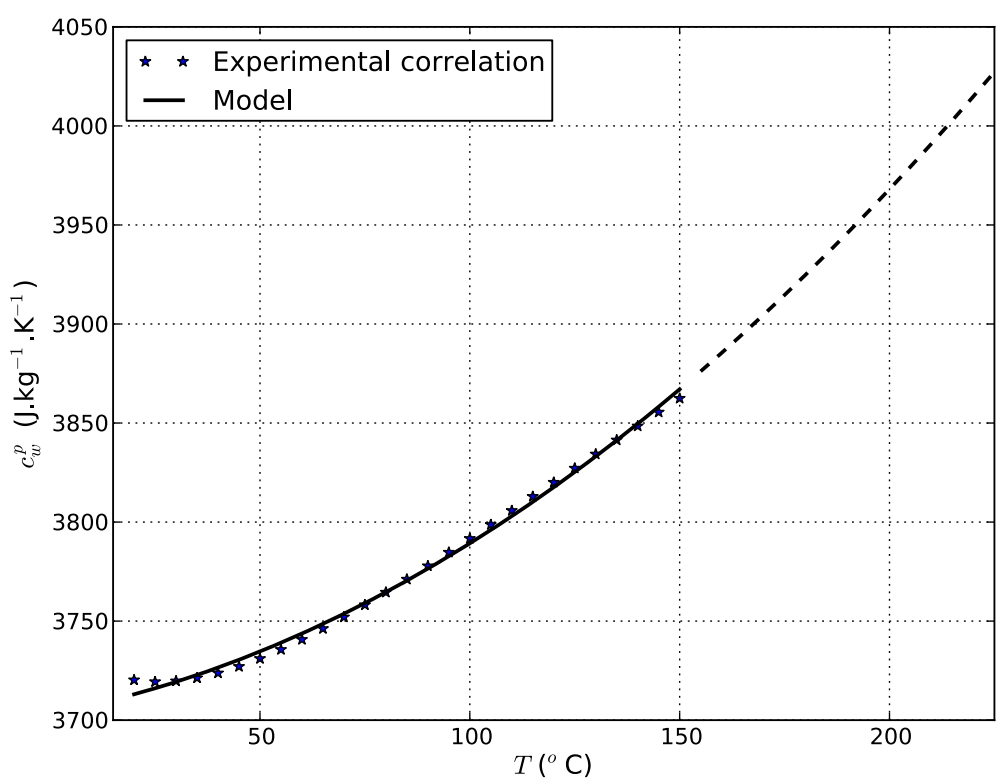

Figure 3 Correlation comparison of Equation (16) with that of Zaytsev and Aseyev (1992).

Comparison of Equation (16) (plain and dotted lines) with the correlation of Zaytsev and Aseyev (1992) (data points) evaluated for a $\mathrm{NaCl}$ mass fraction $w=0.1$.

in which $\alpha_{w}(T)$ and $c_{w}^{p}(T)$ are given by Equations (14) and (16), respectively. In Equations (15), (16), (17), and (18), the quantities

$$
\rho_{w}^{0}, K_{w}, a_{\alpha_{w}}, b_{\alpha_{w}}, c_{\alpha_{w}}, a_{c_{w}^{p}}, b_{c_{w}^{p}}, c_{c_{w}^{p}}, a_{\lambda_{w}}, b_{\lambda_{w}}, c_{\lambda_{w}}, \mu_{w}^{\infty}, \Delta \mu_{w}^{\infty}, \beta, T_{r e f}
$$

are constant parameters which are given in Table 2.

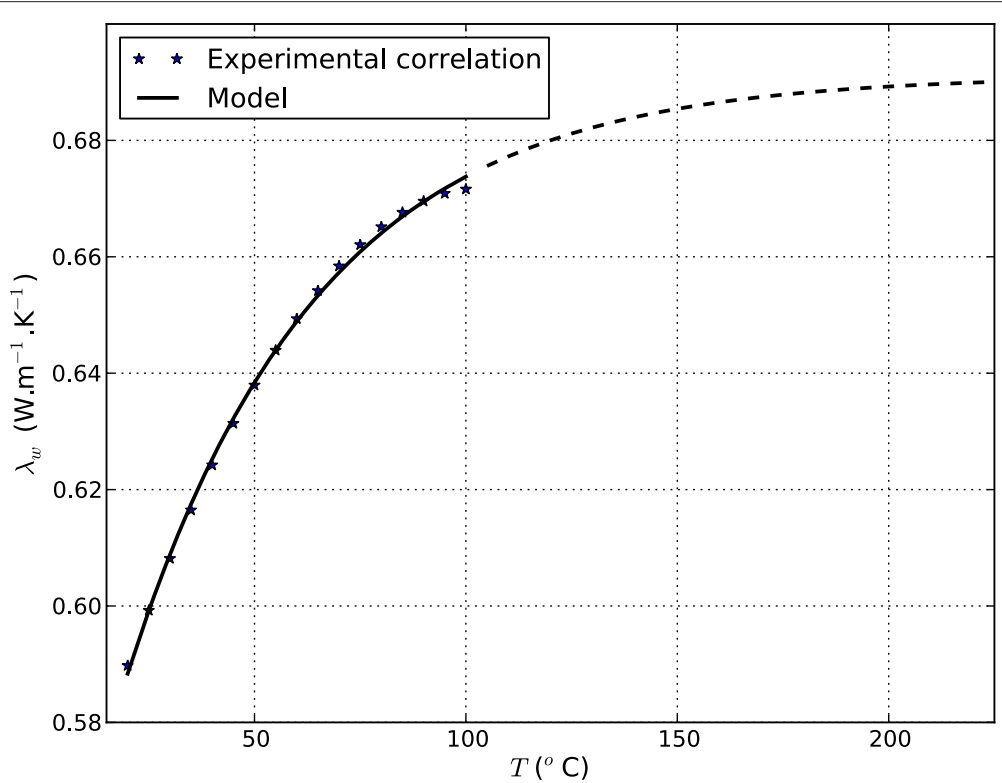

Figure 4 Correlation comparison of Equation (17) with that of Zaytsev and Aseyev (1992).

Comparison of Equation (17) (plain and dotted lines) with the correlation of Zaytsev and Aseyev (1992) evaluated for a $\mathrm{NaCl}$ mass fraction $w=0.1$. 


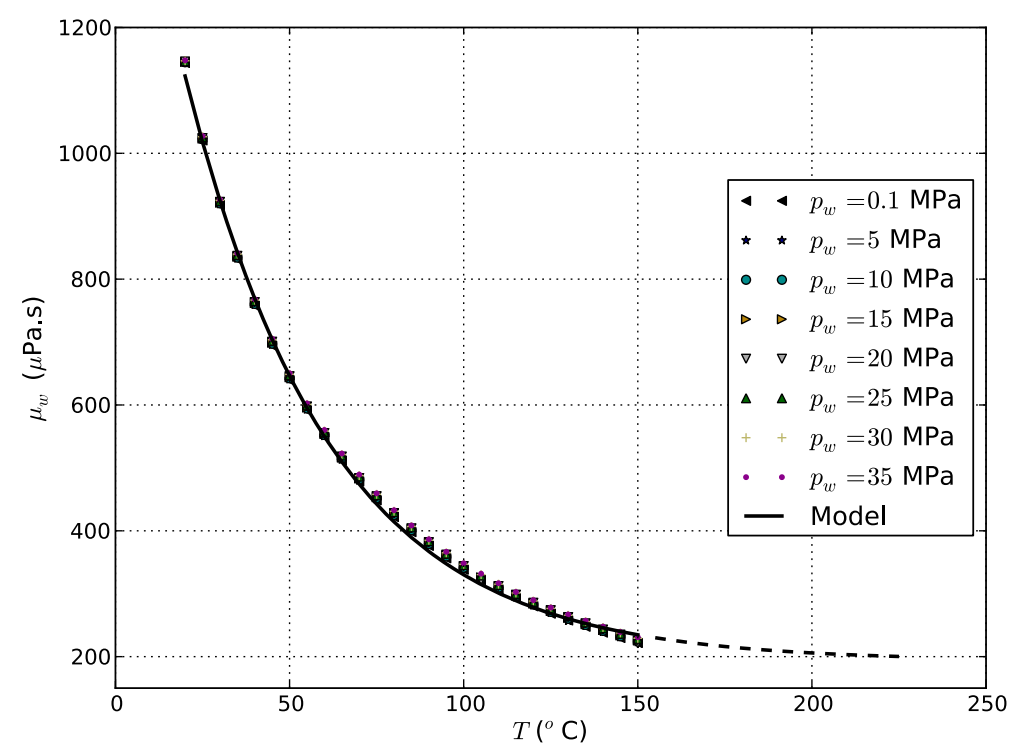

Figure 5 Comparison of Equation (18) with the experimental data of Rowe and Chou (1970).

Complementary to water properties, several assumptions need to be made to calculate homogenized thermal properties. The thermal conductivity $\lambda$ is hereby homogenized by using a classical mixing law

$$
\lambda(T)=(1-\phi) \lambda_{s}(T)+\phi \lambda_{w}(T)
$$

where the lower scripts ' ' $s$ and ' $w$ ' still refer to solid grains and water, respectively. To estimate the thermal conductivity of solid grains, we rewrite Equation (20) for the dry state

$$
\lambda_{\mathrm{dry}}(T)=\left(1-\phi_{0}\right) \lambda_{s}(T)+\phi_{0} \lambda_{\text {air }}(T) .
$$

By neglecting the thermal conductivity of air, we obtain the following:

$$
\lambda_{s}(T) \approx \frac{\lambda_{\mathrm{dry}}(T)}{1-\phi_{0}} .
$$

Since several values are available for $\lambda_{\text {dry }}(T)$ in the literature, we can calculate $\lambda_{s}(T)$ using Equation (22). From experimental studies (see Tables 3 and 4 for the references), we retain a linear variation of $\lambda_{\mathrm{dry}}(T)$ with temperature:

$$
\lambda_{\mathrm{dry}}(T)=a_{\lambda_{d}}+b_{\lambda_{d}} T \text {. }
$$

A similar method is applied to calculate (i) the specific heat at constant stress of solid grains

$$
c_{s}^{\sigma}(T)=\frac{c_{\mathrm{dry}}^{\sigma}(T)-\phi_{0} c_{\mathrm{air}}}{1-\phi_{0}} \quad\left(\text { with } c_{\mathrm{air}}=1,005 \mathrm{~J} \cdot \mathrm{kg}^{-1} \cdot \mathrm{K}^{-1}\right),
$$

from a linear variation of $c_{\mathrm{dry}}^{\sigma}(T)$ (in accordance with experimental data found in the literature):

$$
c_{\mathrm{dry}}^{\sigma}(T)=a_{c_{\mathrm{dry}}}+b_{c_{\mathrm{dry}}} T,
$$

and (ii) the initial and homogenized specific masses

$$
r_{0}=\left(1-\phi_{0}\right) \rho_{s}+\phi_{0} \rho_{w}^{0}=\rho_{\text {dry }}+\phi_{0} \rho_{w}^{0},
$$


Table 2 Properties of brine retained in this work

\begin{tabular}{|c|c|c|c|c|}
\hline Parameter & Unit & Range of values/formula & Comments & Retained value \\
\hline$\overline{\rho_{w}^{0}}$ & $\mathrm{~kg} \cdot \mathrm{m}^{-3}$ & & $\begin{array}{l}\text { Obtained by fitting } \\
\text { Equation (15) with the experimental } \\
\text { correlation of (Rowe and Chou 1970) }\end{array}$ & 1,070 \\
\hline$K_{w}$ & $\mathrm{GPa}$ & $2.0-4.0$ & & 2.2 \\
\hline$\mu_{w}$ & Pa.s & $\mu_{w}^{\infty}+\Delta \mu_{w}^{\infty} \exp \left[\beta\left(T-T_{\text {ref }}\right)\right]$ & $\begin{array}{l}\text { Obtained by fitting } \\
\text { data found in (Kestin et al. 1981) }\end{array}$ & $\begin{array}{l}\mu_{W}^{\infty}=193.4 \times 10^{-6} \text { Pa.s } \\
\Delta \mu_{W}=61.7 \times 10^{-6} \text { Pa.s } \\
\beta=-0.02395 \mathrm{~K}^{-1} \\
T_{\text {ref }}=406.4 \mathrm{~K}\end{array}$ \\
\hline$c_{W}^{p}$ & $J \cdot \mathrm{kg}^{-1} \cdot \mathrm{K}^{-1}$ & $a_{C_{w}^{p}}+b_{c_{w}^{p}}\left(T-T^{1}\right)+c_{c_{w}^{p}}\left(T-T^{1}\right)^{2}$ & $\begin{array}{l}\text { Experimental formula } \\
\text { found in (Zaytsev and Aseyev 1992) }\end{array}$ & $\begin{array}{l}a_{c_{w}^{p}}=3,703.3 \mathrm{~J} \cdot \mathrm{kg}^{-1} \cdot \mathrm{K}^{-1} \\
b_{c_{w}^{p}}=0.395773 \mathrm{~J} \cdot \mathrm{kg}^{-1} \cdot \mathrm{K}^{-2} \\
c_{c_{w}^{p}}=4.64025 \times 10^{-3} \mathrm{~J} \cdot \mathrm{kg}^{-1} \cdot \mathrm{K}^{-3} \\
T^{1}=273.15 \mathrm{~K}\end{array}$ \\
\hline$\alpha_{w}$ & $\mathrm{~K}^{-1}$ & $a_{\alpha_{W}}+2 b_{\alpha_{W}}\left(T-T^{0}\right)+3 c_{\alpha_{w}}\left(T-T^{0}\right)^{2}$ & $\begin{array}{l}\text { Obtained by fitting } \\
\text { Equation (15) with the experimental } \\
\text { correlation of (Rowe and Chou 1970) }\end{array}$ & $\begin{array}{l}a_{\alpha_{W}}=1.3224 \times 10^{-4} \mathrm{~K}^{-1} \\
b_{\alpha_{W}}=4.3315 \times 10^{-7} \mathrm{~K}^{-2} \\
c_{\alpha_{W}}=2.49962 \times 10^{-10} \mathrm{~K}^{-3}\end{array}$ \\
\hline$\lambda_{w}$ & $\mathrm{~W} \cdot \mathrm{m}^{-1} \cdot \mathrm{K}^{-1}$ & $a_{\lambda_{W}}\left(1-b_{\lambda_{W}} \exp \left[-c_{\lambda_{W}}\left(T-T^{1}\right)\right]\right)$ & $\begin{array}{l}\text { Obtained by fitting the } \\
\text { experimental correlation found } \\
\text { in (Zaytsev and Aseyev 1992) }\end{array}$ & $\begin{array}{l}a_{\lambda_{w}}=0.691131 \mathrm{~W} \cdot \mathrm{m}^{-1} \cdot \mathrm{K}^{-1} \\
b_{\lambda_{w}}=0.231942 \\
c_{\lambda_{w}}=2.22312 \times 10^{-2} \mathrm{~K}^{-1} \\
T^{1}=273.15 \mathrm{~K}\end{array}$ \\
\hline
\end{tabular}


Table 3 Typical properties of some sedimentary rocks and their dependence with temperature

\begin{tabular}{|c|c|c|c|}
\hline Property & Unit & Range of values & Comments \\
\hline$\phi_{0}$ & $\%$ & 3 to 35 & Mean value of approximately 15 \\
\hline$\rho_{\text {dry }}$ & $\mathrm{kg} \cdot \mathrm{m}^{-3}$ & 1,900 to 2,600 & Mean value of approximately 2,300 \\
\hline \multirow[t]{2}{*}{$b$} & 1 & 0.65 to 0.80 & Lavoux limestone \\
\hline & & 0.8 to 1.0 & sandstone \\
\hline \multirow[t]{2}{*}{$c_{\mathrm{dry}}^{\sigma}$} & $J \cdot \mathrm{kg}^{-1} \cdot \mathrm{K}^{-1}$ & Approximately 800 & Increase of approximately $15 \%$ \\
\hline & & & if $T \in[20 ; 250]^{\circ} \mathrm{C}$ \\
\hline$K_{\text {int }}$ & $m^{2}$ & $10^{-16}$ to $10^{-9}$ & High variability \\
\hline \multirow[t]{3}{*}{$\lambda_{\text {dry }}$} & $W \cdot m^{-1} \cdot K^{-1}$ & 0.5 to 6 & Mean value of approximately $2 ;$ \\
\hline & & & decrease of approximately $25 \%$ \\
\hline & & & if $T \in[20 ; 250]^{\circ} \mathrm{C}$ \\
\hline$\alpha_{0}$ & $10^{-5} \mathrm{~K}^{-1}$ & 1.3 to 1.5 & Approximately constant if $T \in[50 ; 200]^{\circ} \mathrm{C}$ \\
\hline \multirow[t]{3}{*}{ E } & $\mathrm{GPa}$ & 10 to 92 & Limestones (mean value of approximately 50) \\
\hline & & 2 to 39 & Sandstones (mean value of approximately 15) \\
\hline & & 8 to 22 & Schists (mean value of approximately 14) \\
\hline \multirow[t]{3}{*}{$v$} & 1 & 0.12 to 0.33 & Limestones (mean value of approximately 0.25 ) \\
\hline & & 0.06 to 0.46 & Sandstones (mean value of approximately 0.24 ) \\
\hline & & 0.03 to 0.18 & Schists (mean value approximately 0.08) \\
\hline$\Theta$ & $\mu \mathrm{W} \cdot \mathrm{m}^{-3}$ & 0.3 to 1.8 & \\
\hline
\end{tabular}

$\rho_{w}^{0}$ being the initial density of water. Tables 3 and 4 present a synthetic literature review of sediments and granite properties. It must be noted that these values were obtained on similar rocks to those present in Soultz-sous-Forêts but not on the drilling cores of the reservoir. However, they provide orders of magnitude which are sufficient to reproduce the main mechanisms involved in the reservoir. From this literature review, we took the set of properties given in Tables 2 and 5 as inputs of the numerical model.

Table 4 Typical properties of granite and their dependence with temperature

\begin{tabular}{|c|c|c|c|}
\hline Property & Unit & Range of values & Comments \\
\hline$\overline{\phi_{0}}$ & $\%$ & 0.8 & \\
\hline$\rho_{\text {dry }}$ & $\mathrm{kg} \cdot \mathrm{m}^{-3}$ & 2,500 to 2,800 & Mean value of approximately 2,600 \\
\hline$b$ & 1 & 0.27 to 0.45 & \\
\hline \multirow[t]{2}{*}{$c_{\mathrm{dry}}^{\sigma}$} & $J \cdot \mathrm{kg}^{-1} \cdot \mathrm{K}^{-1}$ & $\sim 800$ & Increase of approximately $25 \%$ \\
\hline & & & if $T \in[20 ; 250]^{\circ} \mathrm{C}$ \\
\hline \multirow[t]{2}{*}{$K_{\text {int }}$} & $m^{2}$ & $10^{-20}$ to $10^{-18}$ & Sane \\
\hline & & $10^{-16}$ to $10^{-11}$ & Fractured \\
\hline \multirow[t]{2}{*}{$\lambda_{\text {dry }}$} & $\mathrm{W} \cdot \mathrm{m}^{-1} \cdot \mathrm{K}^{-1}$ & 2.3 to 3.2 & Decrease of approximately 1.2 \\
\hline & & & if $T \in[20 ; 250]^{\circ} \mathrm{C}$ \\
\hline$\alpha_{0}$ & $10^{-5} \mathrm{~K}^{-1}$ & 1.4 & Approximately constant if $T \in[30 ; 200]^{\circ} \mathrm{C}$ \\
\hline \multirow[t]{2}{*}{$E$} & $\mathrm{GPa}$ & 26 to 78 & Mean value of approximately 59 \\
\hline & & 30 & Approximately constant if $T \in[30 ; 160]^{\circ} \mathrm{C}$ \\
\hline \multirow[t]{2}{*}{$v$} & 1 & 0.10 to 0.38 & Mean value of approximately 0.23 \\
\hline & & 0.25 & Approximately constant if $T \in[30 ; 160]^{\circ} \mathrm{C}$ \\
\hline$\Theta$ & $\mu \mathrm{W} \cdot \mathrm{m}^{-3}$ & 0.7 to 7.6 & \\
\hline
\end{tabular}

From Dwivedi et al. (2008); Maqsood et al. (2004); Park et al. (2004); Schön (2011). 
Table 5 Values of properties taken as inputs of the model

\begin{tabular}{|c|c|c|c|c|}
\hline Property & Unit & Layer 1 & Layer 2 & Layer 3 \\
\hline$\phi_{0}$ & $\%$ & 0.09 & 0.09 & 0.09 \\
\hline$r_{0}$ & $\mathrm{~kg} \cdot \mathrm{m}^{-3}$ & 2,390 & 2,390 & 2,390 \\
\hline E & $\mathrm{GPa}$ & 50 & 50 & 15 \\
\hline$v$ & 1 & 0.25 & 0.25 & 0.24 \\
\hline$b$ & 1 & 0.73 & 0.73 & 0.9 \\
\hline$c_{\mathrm{dry}}^{\sigma}$ & $J . \mathrm{kg}^{-1} \cdot \mathrm{K}^{-1}$ & $950+0.5(T-293.15)$ & $950+0.5(T-293.15)$ & $500+0.5(T-293.15)$ \\
\hline$\lambda_{\text {dry }}$ & $W \cdot m^{-1} \cdot K^{-1}$ & $2.2-0.0025(T-293.15)$ & $2.2-0.0025(T-293.15)$ & $2.6-0.0025(T-293.15)$ \\
\hline$\alpha_{0}$ & $10^{-5} \mathrm{~K}^{-1}$ & 1.4 & 1.4 & 1.4 \\
\hline$\Theta$ & $\mu \mathrm{W} \cdot \mathrm{m}^{-3}$ & 0.5 & 0.5 & 0.5 \\
\hline \multirow[t]{2}{*}{$K_{\text {int }}$} & $\mathrm{m}^{2}$ & $1.0 \times 10^{-14}$ & $1.0 \times 10^{-14}$ & $1.0 \times 10^{-14}$ \\
\hline & & Layer 4 & Layer 5 & Layer 6 \\
\hline$\phi_{0}$ & $\%$ & 0.03 & 0.03 & 0.03 \\
\hline$r_{0}$ & $\mathrm{~kg} \cdot \mathrm{m}^{-3}$ & 2,630 & 2,630 & 2,630 \\
\hline E & $\mathrm{GPa}$ & 59 & 59 & 59 \\
\hline$v$ & 1 & 0.23 & 0.23 & 0.23 \\
\hline$b$ & 1 & 0.36 & 0.36 & 0.36 \\
\hline$c_{\text {dry }}^{\sigma}$ & $J \cdot \mathrm{kg}^{-1} \cdot \mathrm{K}^{-1}$ & $750+0.5(T-293.15)$ & $750+0.5(T-293.15)$ & $750+0.5(T-293.15)$ \\
\hline$\lambda_{\text {dry }}$ & $\mathrm{W} \cdot \mathrm{m}^{-1} \cdot \mathrm{K}^{-1}$ & $2.2-0.0025(T-293.15)$ & $2.2-0.0025(T-293.15)$ & $2.2-0.0025(T-293.15)$ \\
\hline$\alpha_{0}$ & $10^{-5} \mathrm{~K}^{-1}$ & 1.4 & 1.4 & 1.4 \\
\hline$\Theta$ & $\mu \mathrm{W} \cdot \mathrm{m}^{-3}$ & 3.0 & 3.0 & 3.0 \\
\hline$K_{\text {int }}$ & $m^{2}$ & $1.0 \times 10^{-14}$ & $1.0 \times 10^{-14}$ & $1.0 \times 10^{-18}$ \\
\hline
\end{tabular}

\section{Numerical model}

The geological layers considered in this work are slightly adapted from the idealized cross section presented in the paper of Guillou-Frottier (2011) and inspired by the contribution of Genter et al. (1997) and Genter and Traineau (1992). We only consider six layers: the first three layers correspond to the sedimentary cover, i.e. Tertiary to Jurassic marls and clays between 0 and $800 \mathrm{~m}$ of depth, Keuper and Muschelkalk formations between 800 and 1,000 m, and Buntsandstein sandstones between 1,000 and 1,400 m. The granitic basement is represented by three other layers corresponding to the different petrographic units of the granite massif. On top, a thin layer between 1,400 and 1,550 m is considered to reproduce the strongly altered granite from the paleo-erosion surface. The second layer, between 1,550 and 3,700 m, corresponds to a more fractured monzonitic granite in which the homogenized permeability is high. The last layer, located between 3,700 and 5,350 m, corresponds to a crystalline unit made of a porphyritic monzogranite and a fine grained granite. The height of the model corresponds to the height of the measured temperature profile obtained in GPK2, see, e.g. Pribnow and Schellschmidt (2000).

The constitutive equations presented in the two last sections are solved with the Finite Elements Method. The implicit Euler time scheme is used, and the non-linear system giving the increment of the generalized nodal displacements is solved by the Newton-Raphson algorithm. The six layers are meshed with quad elements (see Figure 6) performing an eight-term polynomial interpolation of mechanical displacements and a four-term polynomial interpolation of pressures and temperatures. Below, we denote by $x$ the horizontal direction inside the mesh, $y$ the vertical direction, and $z$ the out-of-plane direction perpendicular to it. For symmetry reasons and to save CPU time, the mesh represents half the reservoir. The boundary conditions of the problem are the following: 


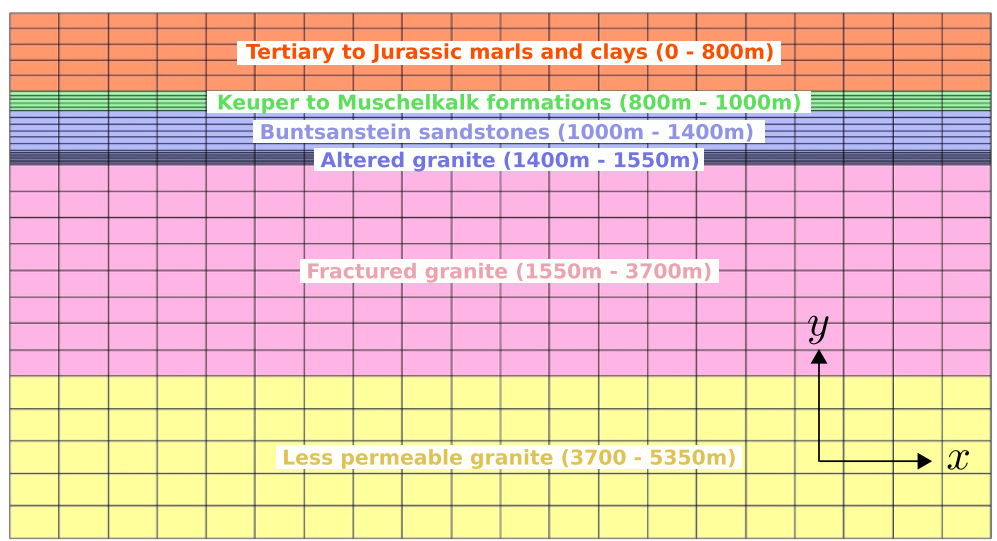

Figure 6 Idealized cross section of the Soultz-sous-Forêts reservoir. The reservoir is $10 \mathrm{~km}$ in width and $5.3 \mathrm{~km}$ in height and is meshed with quad elements. Each color corresponds to a geological layer.

normal mechanical displacement is nil, and no friction is considered on the left and lower boundaries of the domain, whilst the upper boundary is stress-free. A normal stress $\sigma_{x x}^{\text {reg }}$ - with no shear - is applied on the right boundary of the reservoir to account for the regional stress (presented in the next section). For thermal aspects, a temperature of $15^{\circ} \mathrm{C}$ and $208^{\circ} \mathrm{C}$ is imposed on the upper and lower boundary, respectively. These values are directly taken from the experimental temperature profile shown in Figure 7. The thermal flow vanishes on lateral facets. For hydraulic aspects, the flow vanishes on all boundaries except the upper one for which the water pressure approximately equals the atmospheric pressure, i.e. $p_{w}=0.1 \mathrm{MPa}$. Figure 8 summarizes the entire set of boundary conditions.
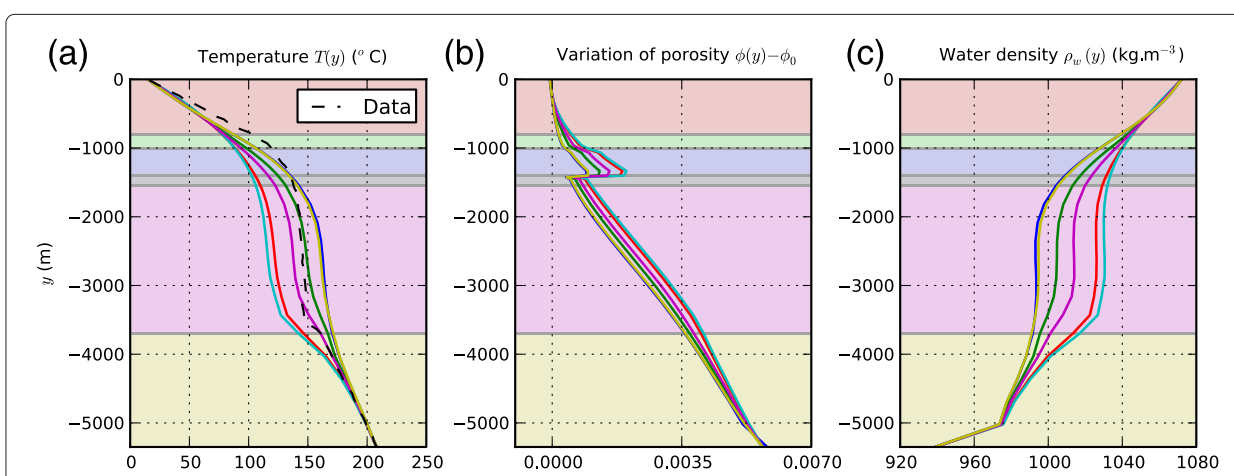

(d)
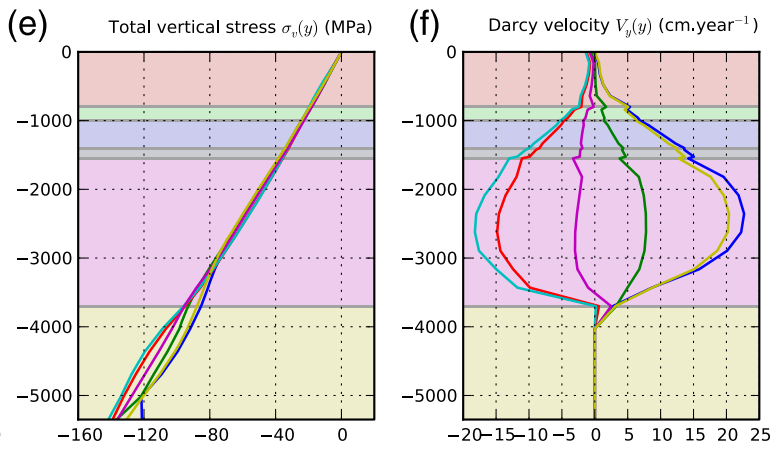

Figure 7 Calculated vertical profiles obtained every $500 \mathrm{~m}$ for $x$ between 0 and 2,500 m. The different background colors correspond to the geological layers considered in the model. (a) Temperature. (b) Variation of porosity. (c) Water density. (d) Water pressure. (e) Total vertical stress. (f) Darcy velocity. 


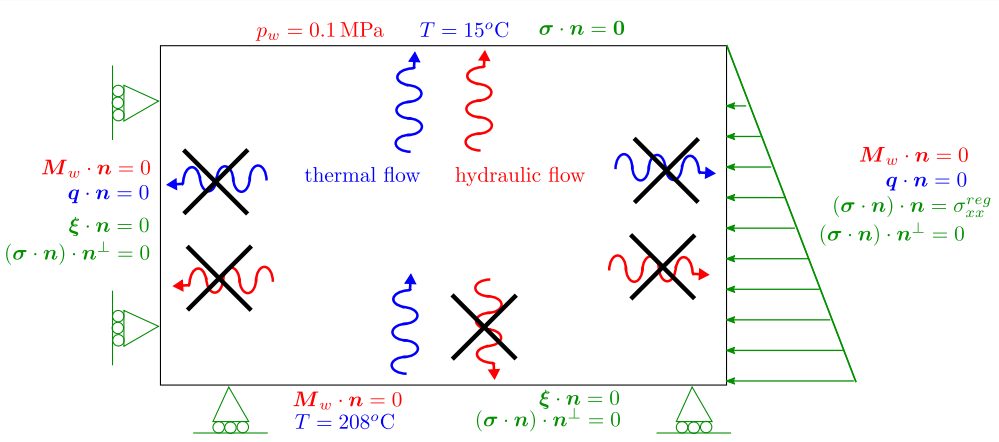

Figure $\mathbf{8}$ Schematic representation of the boundary conditions used in the simulation. Red, hydraulic; blue, thermal; green, mechanical. The ruled arrows represent the thermal and hydraulic flows. $\sigma_{x x}^{\text {reg }}$ corresponds to the regional stress, see Equation (32).

The simulation is carried out with the assumption of plane strains (in the $x, y$ plane) by using the French finite elements software Code_Aster (EDF 2014). Some routines of the latter have been overloaded to integrate the constitutive equations presented above. First, the boundary conditions and gravity are progressively applied during a 'short' period of 100 years, starting from a temperature and a water pressure field presented hereafter. In a second step, the code iterates with a time increment equal to 1,000 years until a stationary state is reached. A stationary state is here defined by using four convergence indicators $I_{n}(X)$ involving the generalized displacements $X \equiv \xi, p_{w}, T$ calculated for different time increments $t_{n}$. More precisely, a stationary state is reached if

$$
I_{n}(X)=\frac{\max _{\text {nodes }}\left[X_{n+1}-X_{n}\right]}{\Delta X_{\max }}<1
$$

for $m$ consecutive time increments $t_{n}$, with $X_{n} \equiv \xi\left(t_{n}\right), p_{w}\left(t_{n}\right), T\left(t_{n}\right)$. The notation 'max $\operatorname{modes}[\star]$ ' indicates the maximal nodal value of the quantity ' $\star$ '. In practice, a value of $m=15$, and the following maximal errors were used:

$$
\Delta \xi_{x, \max }=\Delta \xi_{y, \max }=1 \mathrm{~m}, \quad \Delta p_{w, \max }=0.05 \mathrm{MPa}, \quad \Delta T_{\max }=0.1 \mathrm{~K} .
$$

Once a stationary state is obtained, post-processing operations - such as the calculation of the simulated vertical profiles of temperature and vertical stress - are performed.

\section{Initial state}

To initiate the simulation, several fields like generalized displacements, internal variables and generalized stress have to be prescribed. First, we start the simulation with

$$
\begin{array}{r}
T^{\mathrm{ini}}(x, y)=T_{0}-\frac{y}{H}\left[a_{1}+(y+H)\left(a_{3} y^{3}+a_{4} y^{2}+a_{5} y+a_{6}\right)\right] \times \\
{\left[1-\left(\frac{2 y(y+H)}{3 H^{2}}\right) \cos \left(\frac{2 \pi x}{a_{7}}\right)\right],} \\
T_{0}=15^{\circ} \mathrm{C}, \quad H=5,350 \mathrm{~m}, \quad a_{1}=193.0^{\circ} \mathrm{C}, \\
a_{3}=-2.23166 \times 10^{-12}{ }^{\circ} \mathrm{C} \cdot \mathrm{m}^{-4}, \quad a_{4}=-1.20369 \times 10^{-8}{ }^{\circ} \mathrm{C} \cdot \mathrm{m}^{-3}, \\
a_{5}=1.03248 \times 10^{-5}{ }^{\circ} \mathrm{C} \cdot \mathrm{m}^{-2}, \quad a_{6}=0.0969765 \times 10^{-5}{ }^{\circ} \mathrm{C} \cdot \mathrm{m}^{-1}, \\
a_{7}=2,700.0 \mathrm{~m}, \quad x \in[0 ; 10,000] \mathrm{m}, \quad y \in[-5,350 ; 0] \mathrm{m},
\end{array}
$$

a temperature field rather close of the observed temperature profile in the vertical direction $y$ for $x=0$. A sinusoidal evolution in the horizontal direction $x$ and satisfying the 
boundary conditions are taken into account as an initial perturbation (see Figure 9). The water pressure field is simply initialized by a linear profile

$$
p_{w}^{\mathrm{ini}}(x, y)=-\rho_{w}^{0} g y,
$$

and no mechanical displacements are considered, $\xi^{\text {ini }}=\mathbf{0}$.

The two internal variables used in Code_Aster for the simulation of saturated porous media are the variations of water density $\rho_{w}-\rho_{w}^{0}$ and porosity $\phi-\phi_{0}$. In the present model, these variables are respectively initialized with Equation (15) and the integral form of Equation (6) computed for $\epsilon_{v}=0$

$$
\phi^{\mathrm{ini}}(x, y)-\phi_{0}=\left(b-\phi_{0}\right)\left\{1-\exp \left[3 \alpha_{0}\left(T-T^{0}\right)-\frac{p_{w}-p_{w}^{0}}{K_{w}}\right]\right\} .
$$

Obviously, both formula are evaluated for $T \equiv T^{\text {ini }}(x, y)$ and $p_{w} \equiv p_{w}^{\text {ini }}(x, y)$.

For the initial stress field $\sigma_{i j}^{\text {ini }}$, the linear correlation of (Heineman 1994) giving the experimental regional stress has been used and linearly extrapolated to the top of the reservoir

$$
\sigma_{i j}^{\mathrm{ini}}(x, y)=\sigma_{i j}^{\mathrm{reg}}(x, y)= \begin{cases}-a_{i j} y+b_{i j} & \text { if } y \leq y_{0} \\ \left(-a_{i j} y_{0}+b_{i j}\right) y / y_{0} & \text { if } y_{0} \leq y \leq 0\end{cases}
$$

with $y_{0}=-1,400 \mathrm{~m}$. The values of the $a_{i j}$ and $b_{i j}$ coefficients are given in Table 6 . Note that, as previously written, the horizontal initial stress $\sigma_{x x}^{\text {reg }}$ is used as a stress boundary condition, see Figure 8. Finally, the hydraulic stress is initialized as follows:

$$
\sigma_{p}^{\mathrm{ini}}(x, y)=b \rho_{w}^{0} g y \text {. }
$$

\section{Results and discussion}

First, the numerical dependence of the results to mesh refinement and element types has been investigated. Figure 10 shows vertical profiles of calculated quantities at $x=0$ for two kinds of finite elements (triangles and quads) and mesh sizes starting from 330 to

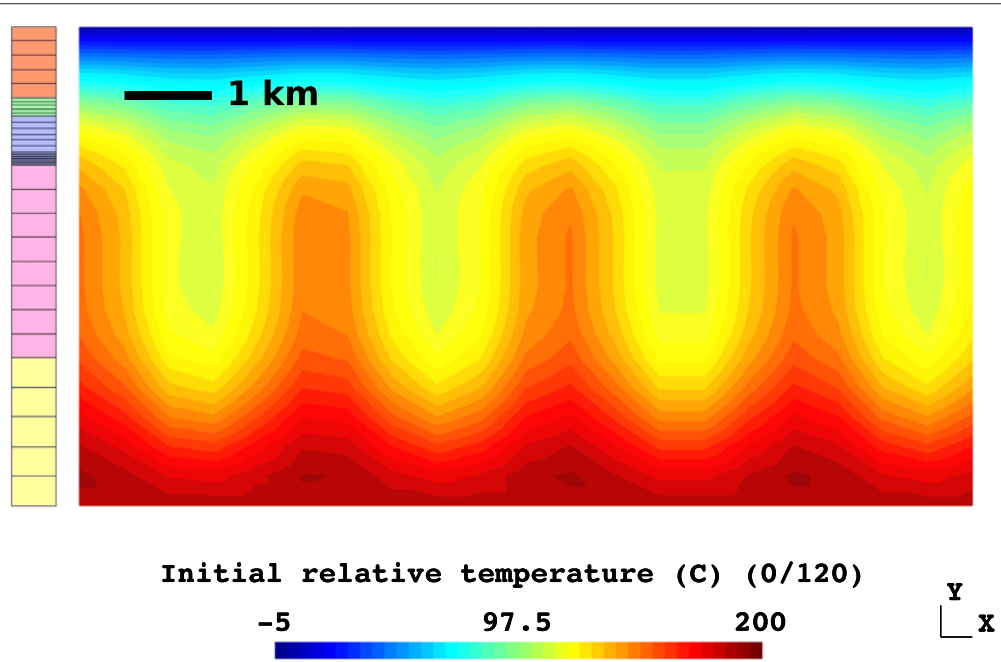

Figure 9 Initial relative temperature used for the simulation. The relative temperature corresponds to the real temperature minus $20^{\circ} \mathrm{C}$. The colored vertical legend indicates the width of geological layers $(5.3 \mathrm{~km}$ in height). 
Table 6 Coefficients used in Equation (32)

\begin{tabular}{cccc}
\hline Component & Notation & $\boldsymbol{a}_{\boldsymbol{i j}}(\mathbf{k P a})$ & $\boldsymbol{b}_{\boldsymbol{i j}}(\mathbf{M P a})$ \\
\hline$\sigma_{x x}$ & $\sigma_{h}$ & -14.9 & 5.92 \\
$\sigma_{x y}$ & $\sigma_{h v}$ & 0.0 & 0.0 \\
$\sigma_{y y}$ & $\sigma_{v}$ & -33.6 & 25.3 \\
$\sigma_{z z}$ & $\sigma_{h}^{\perp}$ & -25.5 & 1.31 \\
\hline
\end{tabular}

2,070 quad elements. The meshes using triangle elements have been obtained by splitting the quad elements along a diagonal, symbolically:

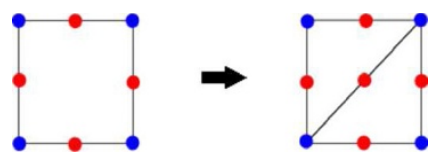

where the blue nodes are the nodes of the linear mesh (used for water pressure and temperature degrees of freedom) and the red ones are the supplementary nodes of the quadratic mesh (used for mechanical displacements). Based on the results of the most refined meshes, it can be concluded that a suitable mesh refinement was reached and that element type have no significant effect on the simulation. Subsequently, we decided to work arbitrarily with quad elements.

The temperature map of the obtained stationary state (see Figure 11) clearly shows convection loops having a size of about $1.3 \mathrm{~km}$. Two other simulations with a model of 20 and

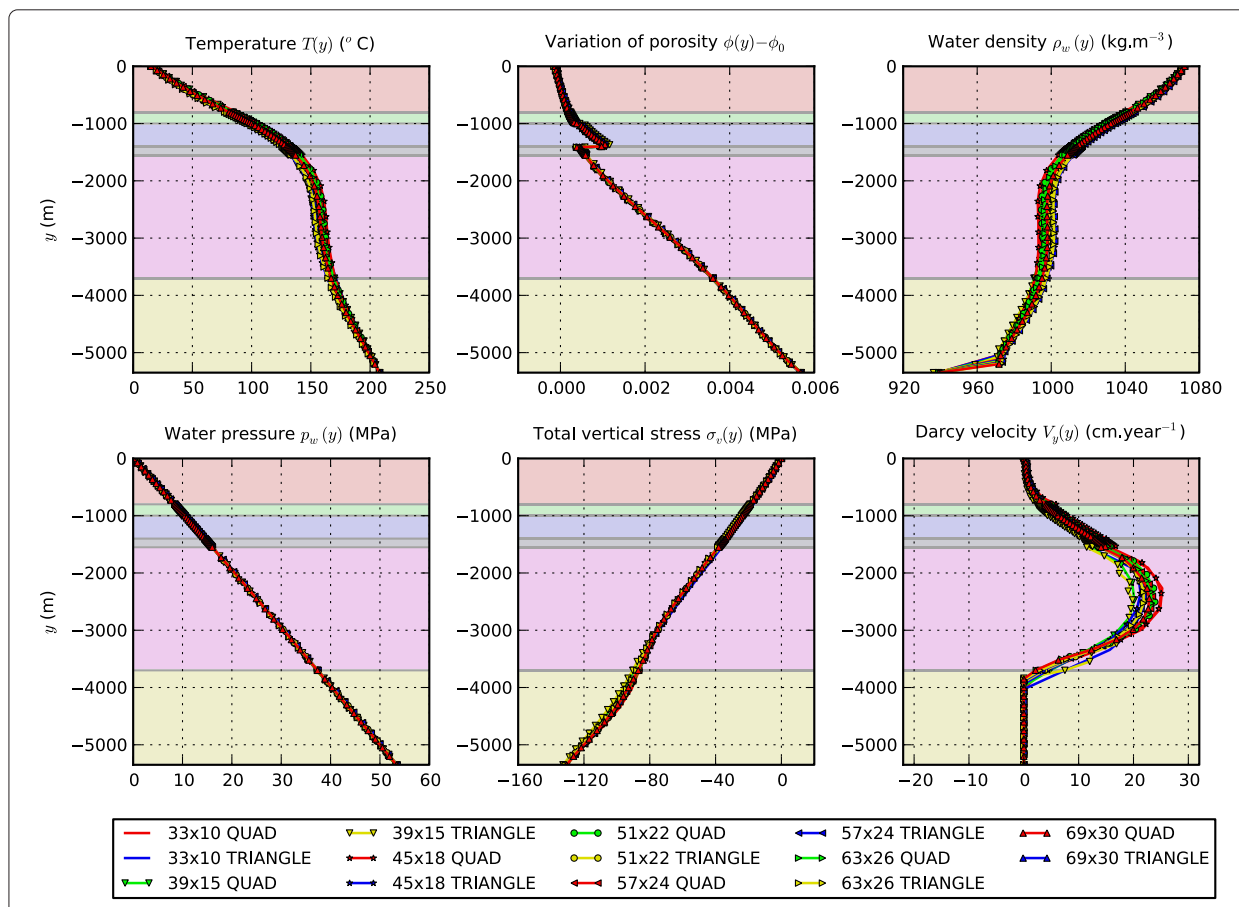

Figure 10 Calculated vertical profiles. Calculated vertical profiles for different mesh refinements and two kinds of finite elements (triangle and quad). The notation $n_{x} \times n_{y}$ indicates the number of quad elements used in the two directions of the mesh. The different background colors correspond to the geological layers considered in the model. 


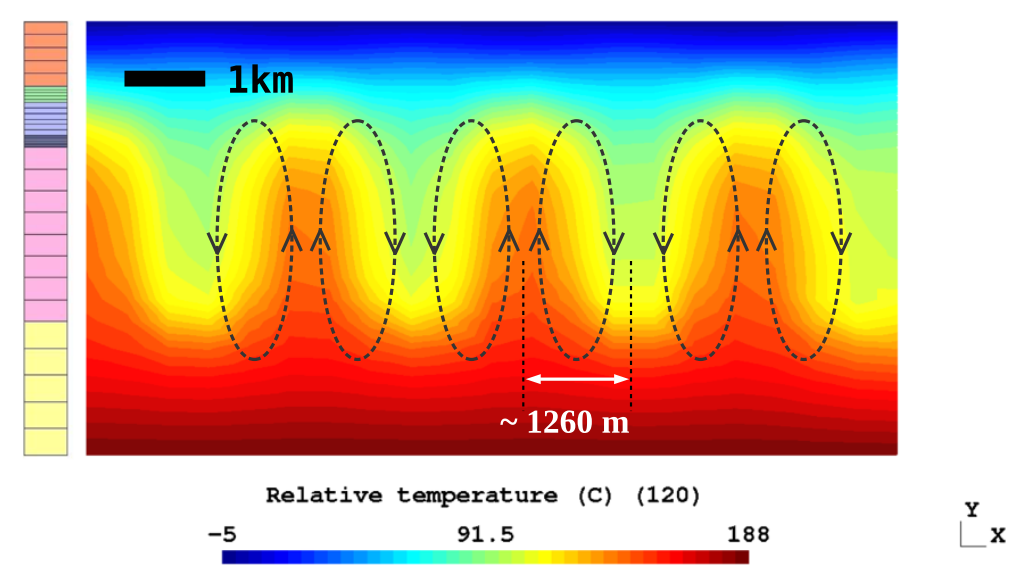

Figure 11 Calculated relative temperature field for a mesh. Mesh size is $10 \mathrm{~km}$ in width and $5.3 \mathrm{~km}$ in height. The relative temperature corresponds to the real temperature minus $20^{\circ} \mathrm{C}$. The dotted circular lines indicate the appearance of convective cells, and the colored vertical legend indicates the width of geological layers.

$30 \mathrm{~km}$ in width proved that the cell width is quasi constant independently of the model width. Furthermore, the value of permeability of the five upper geological layers that trigger the convection seems to be approximately between $1.0 \times 10^{-14}$ and $1.0 \times 10^{-15} \mathrm{~m}^{2}$, see Figure 12.

The temperature map of Figure 11 illustrates the fact that the vertical profile of temperature depends on the horizontal coordinate $x$. To quantify the lateral variation of temperature and other calculated quantities with the horizontal coordinate $x$, different vertical profiles have been plotted in Figure 7a every $500 \mathrm{~m}$ between 0 and 2,500 m. We recall that the value $x=0$ corresponds to the left of the mesh. A lateral variation of about $50^{\circ} \mathrm{C}$ is observed in the interval of depth corresponding to the zone of convective flow. At this stage, the numerical profile reproduces the main tendency of the experimental profile, whilst not fitting exactly the data in particular in the upper part of the convective cell (Buntsandstein layer) where the large scale permeability is possibly underestimated. This difference can also be explained by the fact that we used values of input parameters extracted from the literature without any back analysis to refine them.

The vertical profiles of Figure $7 \mathrm{~b}$ and the section of Figure 13 show that the variation of porosity $\phi-\phi_{0}$ ranges between $0.1 \%$ and $20 \%$ of the initial porosity $\phi_{0}$. These rather low values could be explained by a competition between two mechanisms: (i) a decrease of the porosity due to the lithostatic stress (gravity is applied during the whole simulation) and (ii) an increase due to the dilation of water filling the pores.

To support the last argument, we return to the definition of the Eulerian porosity as the ratio between the actual void volume and the total actual volume of an elementary representative piece of saturated porous medium. Since the dilation of solid grains $\left(\approx 1.4 \times 10^{-5}\right.$, quasi independent of temperature $)$ is about ten times smaller than the dilation of water $\left(\geq 1.5 \times 10^{-4}\right.$ at $\left.50^{\circ} \mathrm{C}\right)$, and since the system is globally unconfined and drained because of the upper stress-free and drained boundary, one may surmise that an increase of temperature will greatly increase the volume of water whilst keeping the volume of solid grains quasi constant, thus explaining a possible increase of porosity due to 


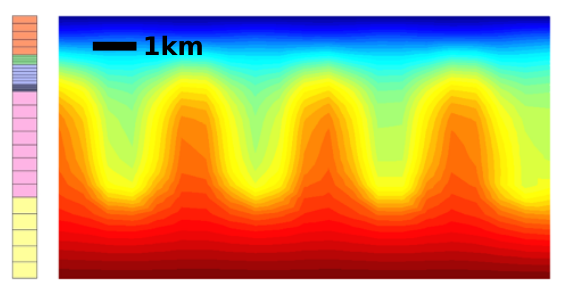

$$
K_{i n t}=1.0 \times 10^{-14} \mathrm{~m}^{2}
$$

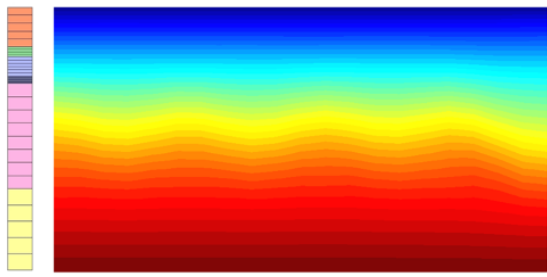

$$
K_{\text {int }}=1.0 \times 10^{-15} \mathrm{~m}^{2}
$$

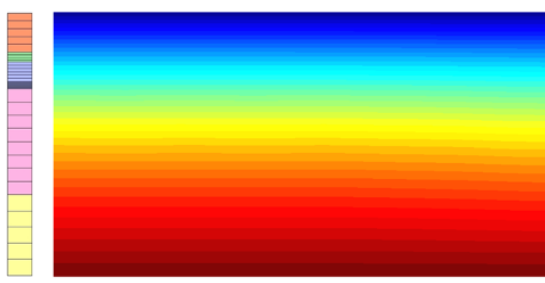

$$
K_{\text {int }}=1.0 \times 10^{-16} \mathrm{~m}^{2}
$$

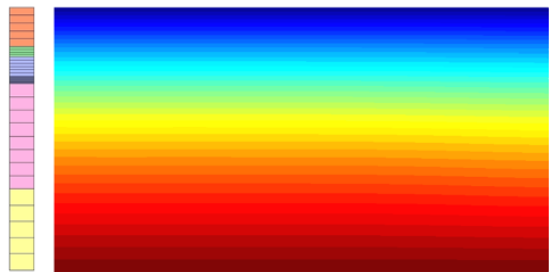

$$
K_{\text {int }}=1.0 \times 10^{-17} \mathrm{~m}^{2}
$$

Final relative temperature (C) $(172 / 172)$

$$
-5
$$

91.5 188

Figure 12 Final relative temperature obtained for different values of permeability. In this figure, $K_{\text {int }}$ stands for the permeability in the five upper geological layers, the permeability of the last layer being constant and equal to $\mathbf{1 . 0} \times \mathbf{1 0}^{-\mathbf{- 1 8}} \mathrm{m}^{2}$.

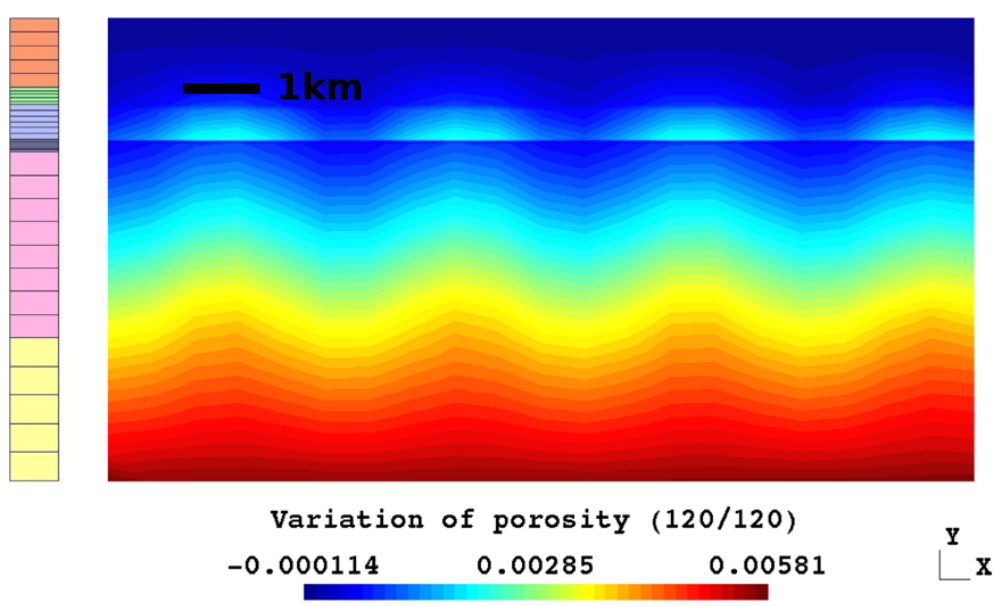

Figure 13 Variation of porosity $\phi-\phi_{0}$ between the (final) stationary state and the reference (initial) state. Model of $10 \mathrm{~km}$ in width, $5.3 \mathrm{~km}$ in height. The vertical colored legend indicates the width of geological layers. 


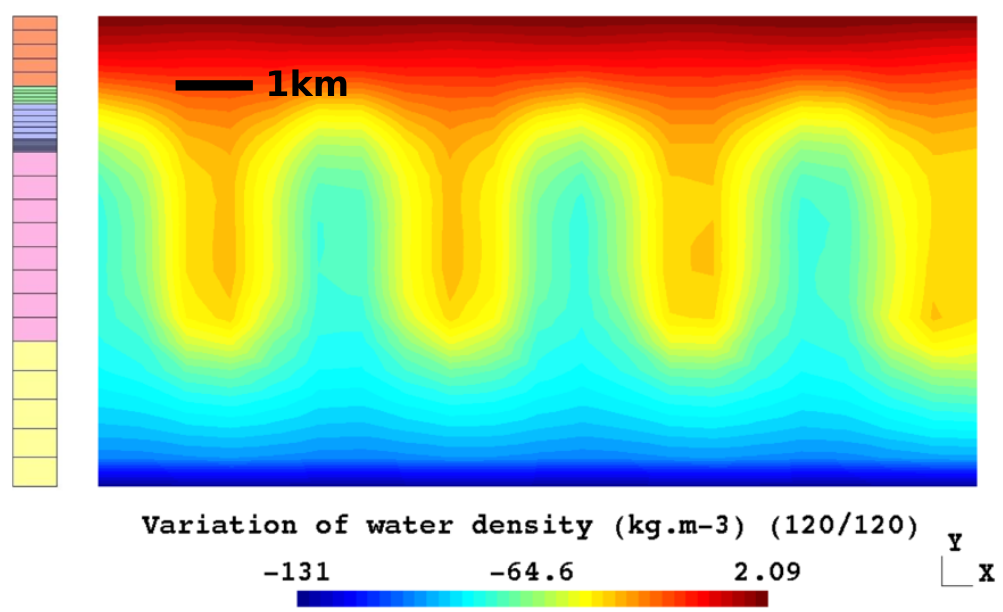

Figure 14 Variation of water density $\rho_{w}-\rho_{w}^{0}\left(\mathrm{~kg}^{\mathrm{m}} \mathrm{m}^{-3}\right)$ between the (final) stationary state and the reference (initial) state. Model of $10 \mathrm{~km}$ in width and $5.3 \mathrm{~km}$ in height. The vertical colored legend indicates the width of geological layers.

thermal effects. The vertical profiles presented in Figure $7 \mathrm{~b}$ indicate that the two mentioned contradictory effects seem to globally balance. Finally, one should keep in mind that no dependences of the bulk moduli (solid framework and water) with temperature and pressure have been taken into account, and that these dependences may significantly affect the variation of porosity.

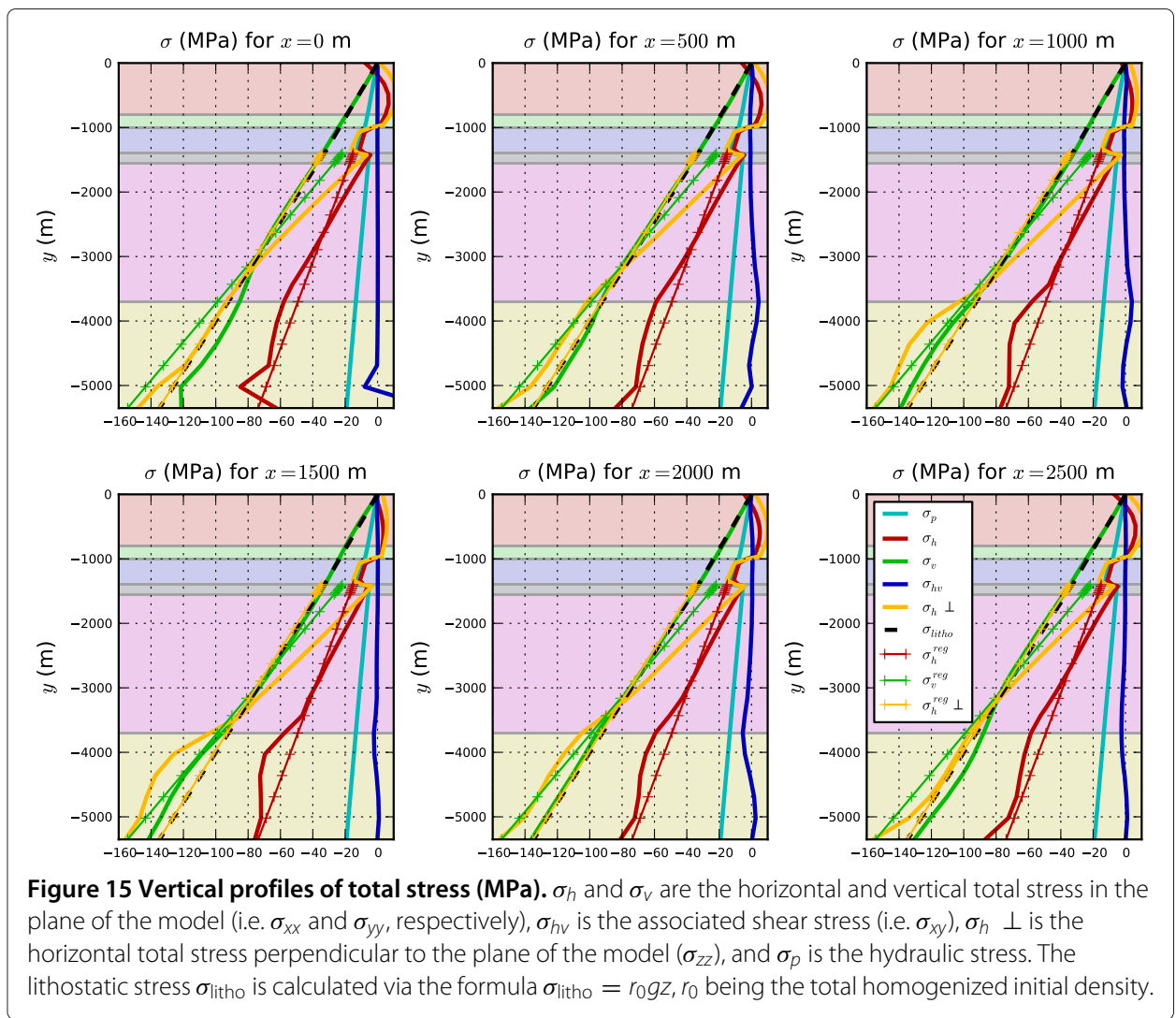


For hydraulic aspects, we note from the vertical profiles plotted in Figure 7 that the field of water pressure keeps globally linear with depth. The order of magnitude of the vertical Darcy velocity $V_{y}=\boldsymbol{M}_{w} \cdot \boldsymbol{e}_{y} / \rho_{w}$ in the fractured granite is $20 \mathrm{~cm}_{\text {.year }}{ }^{-1}$, which is in accordance with the value $15 \mathrm{~cm}$.year ${ }^{-1}$ obtained by (Guillou-Frottier et al. 2013) using slightly different permeability profiles. The change of sign of $V_{y}$ inside the convective loop (Figure 7f) is obviously the consequence of ascending and descending movements of water triggered by the variation of its density (see Figure 14). Globally, the impact of hydraulics on mechanics seem to be rather low. Indeed, if we consider the vertical profiles of total stress pictured in Figure 15, calculated for different values of $x$, one can see that the hydraulic stress $\sigma_{p}$ keeps relatively small (less than $25 \%$ ) relative to total stresses whatever the position of the vertical profile. We conclude that effective stress and total stress are approximately the same in this model. Furthermore, the shear stress $\sigma_{h v}$ corresponding to the shear associated with the horizontal and vertical directions is negligible. It is then possible to claim that the total Cauchy stress tensor keeps diagonal. In addition, the vertical stress $\sigma_{v}$ remains close to the initial lithostatic stress $\sigma_{\text {litho }}=r_{0} g z$, showing that thermo-hydraulic phenomena do not have a great impact on the vertical stress state in the reservoir. Of course, this conclusion obtained in two dimensions and with the assumption of plane strains could be different with a three-dimensional model including the main faults present in the reservoir.

\section{Conclusions}

The two-dimensional numerical model developed in this work lead us to the following main conclusions:

- A stationary convective solution at large scale is highlighted. The order of magnitude of the convective cell size in the reservoir is about $1.3 \mathrm{~km}$, a value being independent of the model width. A periodic pair of cells is then $2.6 \mathrm{~km}$ wide. We insist on the fact that the unicity of this solution is not guaranteed. Furthermore, the way the initial conditions influence the final result is a difficult task accounting for the strong nonlinearity of the constitutive equations. The unicity of this solution, its stability, and the way initial conditions may influence the final results will be analysed in a future work.

- The order of magnitude of the maximal vertical Darcy velocity is $20 \mathrm{~cm}_{\text {.year }}{ }^{-1}$, a value confirmed by previous works found in the literature.

- The field of water pressure keeps globally linear with depth, and the influence of thermo-hydraulic coupling on the vertical stress state of the reservoir is rather low.

- The large scale convection is triggered with a permeability in the five upper geological layers of about $1.0 \times 10$ to $1.0 \times 10^{-15} \mathrm{~m}^{2}$.

One should keep in mind that these first conclusions have been obtained with a twodimensional model under the assumption of plane strains. They should consequently be confirmed or infirmed by a three-dimensional model, accounting for the presence of main faults in the reservoir. Works are currently in progress to follow this route and to make our model more realistic. 


\section{Authors' contributions}

VM carried out the numerical study and wrote the first version of the paper. The three other authors conducted the final version of the manuscript. All authors read and approved the final manuscript.

\section{Acknowledgements}

The author are grateful to the reviewers for their constructive expertise and the useful hints aimed at improving the content of our manuscript. They also gratefully acknowledge Dr. François Cornet for very helpful discussions. This work has been published under the framework of the LABEX ANR-11-LABX-0050-G-EAU-THERMIE-PROFONDE and benefits from a funding from the state managed by the French National Research Agency as part of the 'Investments for the Future' program.

\section{Author details}

${ }^{1}$ ICube Laboratory, UMR CNRS 7357, 72, Route du Rhin, CS 315, F-67411, IIlkirch CEDEX, France. ${ }^{2}$ GEIE EMC, Route de Soultz, BP 40038, F-67250, Kutzenhausen, France. ${ }^{3}$ EOST, 5 rue René Descartes, F-67084, Strasbourg CEDEX, France.

Received: 14 April 2014 Accepted: 20 November 2014

Published online: 17 December 2014

\section{References}

Bächler D, Kohl T (2005) Coupled thermal-hydraulic-chemical modelling of enhanced geothermal systems. Geophys J Int 161:533-548

Bächler D, Kohl T, Rybach L (2003) Impact of graben-parallel faults on hydrothermal convection — Rhine Graben case study. Phys Chem Earth 28:431-441

Cerminara M, Fasano A (2012) Modeling the dynamics of a geothermal reservoir fed by gravity driven flow through overstanding saturated rocks. J Volcanology Geothermal Res 233-234:37-54

Coussy O (2004) Poromechanics. John Wiley \& Sons, The Atrium, Southern Gate, Chichester, England

Dwivedi RD, Goel RK, Prasad WR, Sinha A (2008) Thermo-mechanical properties of Indian and other granites. Int J Rocks Mech Mining Sci 45:303-315

EDF (2014) Code_Aster Open Source - General FEA software. www.code-aster.org

Elder JW (1967) Transient convection in a porous medium. J Fluid Mech 27:609-623

Francke H, Thorade M (2010) Density and viscosity of brine: an overview from a process engineers perspective. Chemie der Erde 70:23-32

Genter A, Castaing C, Dezayes C, Tenzer H, Traineau H, Villemin T (1997) Comparative analysis of direct (core) and indirect (borehole imaging tools) collection of fracture data in the Hot Dry Rock Soultz reservoir (France). J Geophys Res 102:15419-15431

Gelet R, Loret B, Khalili N (2012) A thermo-hydro-mechanical coupled model in local thermal non-equilibrium for fractured HDR reservoir with double porosity. J Geophys Res 117:1-23

Genter A, Traineau H (1992) Borehole EPS1, Alsace, France: preliminary geological results from granite core analyses for Hot Dry Rock research. Sci Drilling 3:205-214

Genter A, Evans K, Cuenot N, Fritsch D, Sanjuan B (2010) Contribution of the exploration of deep crystalline fractured reservoir of Soultz to the knowledge of enhanced geothermal systems (EGS). Comptes Rendus Géosci 342:502-516

Guillou-Frottier L (2011) La convection hydrothermale et les ressources associées. Géosciences 13:40-47

Guillou-Frottier L, Carré C, Bourgine B, Bouchot V, Genter A (2013) Structure of hydrothermal convection in the Upper Rhine Graben as inferred from corrected temperature data and basin-scale numerical models. J Volcanology Geothermal Res 256:29-49

Guimaraes AO, Viana DA, Cordeiro TC, Sampaio JA, da Silva EC, Toledo R, Ribeiro HJPS, Carrasquilla AAG, Vargas H (2013) On the use of photothermal methods for thermal characterization of sedimentary rocks from the Parana basin in Brazil. Mar Petroleum Geol 43:121-126

Heineman B (1994) Results of scientific investigations at the HDR test site Soultz-sous-Forêts. SOCOMINE report

Kappelmeyer O, Haenel R (1974) Geothermics with special reference to application. vol. 4. Gebrüder Borntraeger, Berlin, Germany

Kestin J, Ezzat Khalifa H, Correia RJ (1981) Tables of the dynamic and kinematic viscosity of aqueous $\mathrm{NaCl}$ solutions in the temperature range $20-150^{\circ} \mathrm{C}$ and the pressure range 0.1-35 MPa. J Phys Chem Ref Data 10:71-87

Kirk SS, Williamson DM (2012) Structure and thermal properties of porous geological materials. AIP Conf Proc $1426: 867-870$

Kohl T, Mégel T (2007) Predictive modeling of reservoir response to hydraulic stimulations at the European EGS site Soultz-sous-Forêts. Int J Rock Mech Mining Sci 44:1118-1131

Kohl T, Evans KF, Hopkirk RJ, Rybach L (1995) Coupled hydraulic, thermal and mechanical considerations for the simulation of hot dry rock reservoirs. Geothermics 3:345-359

Kohl T, Bächler D, Rybach L (2000) Steps towards a comprehensive thermo-hydraulic analysis of the HDR test site Soultz-sous-Forêts. Proceedings World Geothermal Congress. Kyushu-Tohoku, Japan, 2671-2676

Magri F, Akar T, Gemici U, Pekdeger A (2010) Deep geothermal groundwater flow in the Seferihisar-Balçova area, Turkey: results from transient numerical simulations of coupled fluid flow and heat transport processes. Geofluids 10:388-405

Maqsood A, Gul IH, Anis-ur-Rehman M (2004) Thermal transport properties of granites in the temperature range 253-333. J Phys D: Appl Phys 37:1405-1409

May-Crespo J, Martinez-Torres P, Alvarado-Gil JJ, Quintana P, Vilca-Quispe L (2012) Photothermal radiometry characterization of limestone rocks from the peninsula of Yucatan. Int J Thermophys 33:1908-1915

Park C, Synn JH, Shin HS, Cheon DS, Lim HD, Jeon SW (2004) An experimental study on the thermal characteristics of rock at low temperatures. Int J Rocks Mech Mining Sci 41(3):367-368

Pasquale V, Gola G, Chiozzi P, Verdoya M (2011a) Thermophysical properties of the Po Basin rocks. Geophys J Int 186:69-81 
Pasquale V, Verdoya M, Chiozzi P (2011b) Groundwater flow analysis using different geothermal constraints: the case study of Acqui Terme area, northwestern Italy. J Volcanology Geothermal Res 199:38-46

Pribnow D, Schellschmidt R (2000) Thermal tracking of upper crustal fluid flow in the Rhine graben. Geophys Res Lett 13:1957-1960

Rowe AMJ, Chou JCS (1970) Pressure-volume-temperature-concentration relation of aqueous $\mathrm{NaCl}$ solutions. J Chem Eng Data 15:61

Segall P, Rice JR (2006) Does shear heating of pore fluid contribute to earthquake nucleation? J Geophys Res 111:1-17 Schön JH (2011) Physical properties of rocks - a workbook. Handbook of Petroleum Exploration and Production. Elsevier, Oxford, UK

Touloukian YS, Judd WR, Roy RF (1981) Physical properties of rocks and minerals. McGraw-Hill/CINDAS data series on material properties: Group II, Properties of special materials. McGraw-Hill, New York, USA

Zaytsev ID, Aseyev GG (1992) Properties of aqueous solutions of electrolytes. CRC Press, Boca Raton, USA

doi:10.1186/s40517-014-0017-x

Cite this article as: Magnenet et al:: Two-dimensional THM modelling of the large scale natural hydrothermal circulation at Soultz-sous-Forêts. Geothermal Energy 2014 2:17.

Submit your manuscript to a SpringerOpen ${ }^{\odot}$ journal and benefit from:

- Convenient online submission

- Rigorous peer review

- Immediate publication on acceptance

- Open access: articles freely available online

- High visibility within the field

- Retaining the copyright to your article

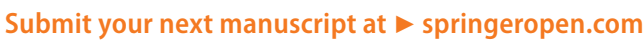

